\section{IUCrJ}

ISSN 2052-2525

CHEMISTRY|CRYSTENG

\title{
Thermomechanical effect in molecular crystals: the role of halogen-bonding interactions
}

\author{
Sudhir Mittapalli, ${ }^{a}$ D. Sravanakumar Perumalla, ${ }^{\mathrm{b}}$ Jagadeesh Babu Nanuboluc ${ }^{\mathrm{c}}$ and \\ Ashwini Nangia ${ }^{a, d *}$ \\ aschool of Chemistry, University of Hyderabad, Professor C. R. Rao Road, Gachibowli, Hyderabad 500 046, India, \\ ${ }^{\mathbf{b}}$ Department of Inorganic and Physical Chemistry, Indian Institute of Science, Bengaluru 500016 , India, ${ }^{\mathbf{c} C S I R-I n d i a n}$ \\ Institute of Chemical Technology, Tarnaka, Hyderabad 500 007, India, and ${ }^{\mathbf{d} C S I R-N a t i o n a l ~ C h e m i c a l ~ L a b o r a t o r y, ~ D r ~}$ \\ Homi Bhabha Road, Pune 411 008, India. *Correspondence e-mail: ashwini.nangia@gmail.com
}

Received 12 May 2017

Accepted 10 October 2017

Edited by M. Eddaoudi, King Abdullah University, Saudi Arabia

Keywords: halogen bonds; hydrogen bonds; materials science; polymorphism; salinazid; crystal engineering; mechanochemistry; molecular crystals; materials modelling.

CCDC references: $1579384 ; 1548278$; 1548279; 1548280; 1548281; 1548282; $1548283 ; 1548284 ; 1548285$

Supporting information: this article has supporting information at www.iucrj.org

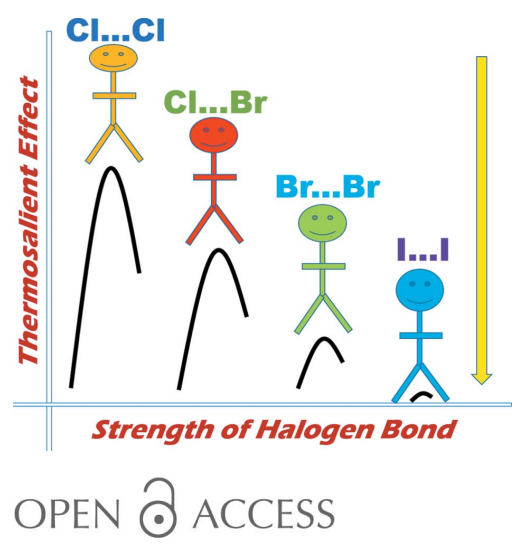

The design and synthesis of mechanically responsive materials is interesting because they are potential candidates to convert thermal energy into mechanical work. Reported in this paper are thermosalient effects in a series of halogen derivatives of salinazids. The chloro derivative, with higher electronegativity and a weaker inter-halogen bond strength $(\mathrm{Cl} \cdots \mathrm{Cl})$ exhibits an excellent thermal response, whereas the response is weaker in the iodo derivative with stronger I . . I halogen bonding. 3,5-Dichlorosalinazid (Compound-A) exists in three polymorphic forms, two room-temperature polymorphs (Forms I and II) and one high-temperature modification (Form III). The transformation of Form I to Form III upon heating at $328-333 \mathrm{~K}$ is a reversible thermosalient transition, whereas the transformation of Form II to Form III is irreversible and nonthermosalient. 3,5-Dibromo- (Compound-B) and 3-bromo-5-chloro(Compound-C) salinazid are both dimorphic: the Form I to Form II transition in Compound-B is irreversible, whereas Compound-C shows a reversible thermosalient effect (362-365 K). In the case of 3,5-diiodosalinazid (CompoundD) and 3,5-difluorosalinazid (Compound-E), no phase transitions or thermal effects were observed. The thermosalient behaviour of these halosalinazid molecular crystals is understood from the anisotropy in the cell parameters (an increase in the $a$ axis and a decrease in the $b$ and $c$ axes upon heating) and the sudden release of accumulated strain during the phase transition. The dihalogen salinazid derivatives (chlorine to iodine) show a decrease in thermal effects with an increase in halogen-bond strength. Interestingly, Compound-B shows solid-state photochromism in its polymorphs along with the thermosalient effect, wherein Form I is cyan and Form II is light orange.

\section{Introduction}

The development of mechanically responsive materials which respond to external stimuli such as heat, light and pressure is important because these materials are known to be selfactuating and energy-harvesting (Kim et al., 2013; Morimoto \& Irie, 2010; McCrone, 1965; Panda et al., 2015). They have wide-ranging applications, such as artificial muscles and biomimetic and technomimetic materials (Cabane et al., 2012; Ikeda et al., 2007; Lehn, 2002; Mather, 2007; Rowan, 2009; Sagara \& Kato, 2009; Sato, 2016; Takashima et al., 2012). The design of smart materials with reversibility, stability and controlled properties is challenging (Mao et al., 2016; Park et $a l ., 2016)$. The properties of solid-state crystalline materials depend not only on the molecular functional groups but, more significantly, on the intermolecular interactions, hydrogen bonding and molecular packing in the crystal structure. The mobility of molecules in the solid state is limited and hence when an external stimulus is applied the molecules become 
activated and undergo a chemical reaction or polymorphic phase change along with mechanical movement, referred to as dynamic molecular crystals, or without movement (Lieberman et al., 2000; Naumov et al., 2015; Swapna et al., 2016; Sato, 2016). The dynamic behaviour of crystals towards applied heat (thermosalient effects; Lusi \& Bernstein, 2013; Nath et al., 2014; Sahoo et al., 2013; Skoko et al., 2010; Takeda \& Akutagawa, 2016) or light energy (photosalient effect; Medishetty et al., 2015) can occur with or without a change in the crystal morphology and packing of the molecules. The first reported example of the thermosalient effect was (phenylazophenyl)palladium hexafluoroacetylacetonate, an organometallic compound whose crystals were shown to jump/expand during phase transition (Etter \& Siedle, 1983). Yao et al. (2014) reported the $\mathrm{Ni}$ complex $\left[\mathrm{Ni}^{\mathrm{II}}(\mathrm{en})_{3}\right](\mathrm{ox}) \quad[\mathrm{en}=$ ethylenediamine; ox $=$ oxalate] with a reversible shape change and deformation of the crystals due to a $90^{\circ}$ rotation of the oxalate anion during phase transition and anisotropy in the unit-cell parameters. Das et al. (2010) reported deformation of $(S, S)$ octa-3,5-diyn-2,7-diol crystals due to the anisotropy in the cell parameters and a change in the stacking angle from 54 to $51^{\circ}$. Panda et al. (2016) reported positive and negative thermal expansion in thermosalient $N^{\prime}$-2-propylydene-4-hydroxybenzohydrazide crystals. There have been a few reports of dynamic organic molecular crystals exhibiting jumping, curling, rolling and explosion upon external stimulus (Kim et al., 2013; Koshima et al., 2009; Kumar et al., 2013; Baker, 2017; Uchida et al., 2008).

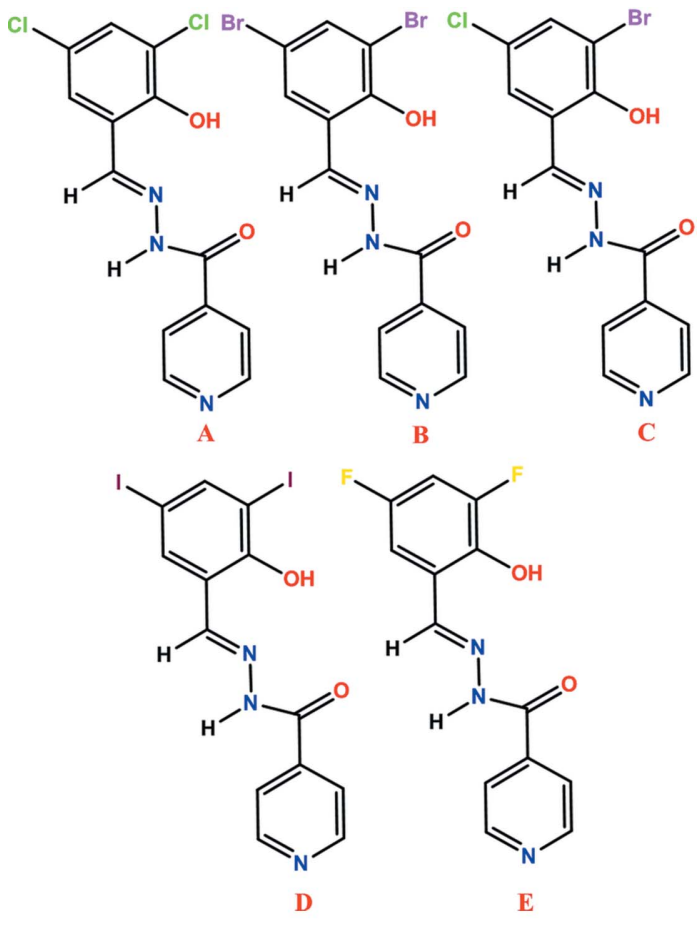

Scheme 1

In the present investigation, a series of di-halosubstituted $(\mathrm{Cl}, \mathrm{Br}, \mathrm{I}$ and $\mathrm{F})$ Schiff bases showing thermal responses and solid-state photochromism are reported. The dichloro(Compound-A), dibromo- (Compound-B) and 3-bromo-5- chloro- (Compound-C) salinazid derivatives showed jumping/ breaking/cracking of the crystals during phase transformation. Phase transformation with a change in $Z^{\prime}$ from 1 to 2 was observed for Compound-B, with significant changes in the molecular conformation (dihedral angles), hydrogen bonding and crystal packing. Crystals of Compound-D and E (diiodoand difluoro-salinazid) did not show any type of thermal response on heating. Chemical diagrams are shown in Scheme 1 , and the 2-hydroxybenzylidene isonicotinohydrazide skeleton is referred to as salinazid.

\section{Experimental}

For the preparation of dichlorosalinazid Compound-A, $(E)$ $N^{\prime}$-(3,5-dichloro-2-hydroxybenzylidene)isonicotinohydrazide, the conventional reaction with azeotropic removal of water (Safin et al., 2014) was followed. Isonicotinohydrazide $(1 \mathrm{mmol}, 137 \mathrm{mg})$ was dissolved in anisole $(10 \mathrm{ml})$ in a $100 \mathrm{ml}$ round-bottomed flask fitted with a Dean-Stark set up. 3,5Dichlorosalicylaldehyde $(1 \mathrm{mmol}, 191 \mathrm{mg})$ was added to the solution. The reaction mixture turned light yellow (after $10 \mathrm{~min}$ ) and it was refluxed for $4 \mathrm{~h}$. The solution was concentrated by removing the solvent and was then washed with $n$-hexane 3-4 times to remove unwanted by-products. Light-cyan crystals of dichloro Compound-A were obtained in $80 \%$ yield. The same procedure was followed for the synthesis of Compounds-B, C, D and E, and their structures were confirmed by ${ }^{1} \mathrm{H}$ NMR and ${ }^{13} \mathrm{C}$ NMR (Figs. S1 $a-\mathrm{S} 1 h$ in the supporting information) and finally by single-crystal X-ray diffraction.

\subsection{Compound-A}

${ }^{1} \mathrm{H}$ NMR $\left(400 \mathrm{MHz}, d_{6}\right.$-DMSO, $298 \mathrm{~K}, \delta$ in p.p.m., Fig. S1a): $12.73(s, 1 \mathrm{H}), 12.30(s, 1 \mathrm{H}), 8.82(d, J=2.4 \mathrm{~Hz}, 2 \mathrm{H}), 7.86(d, J=$ $2.8 \mathrm{~Hz}, 2 \mathrm{H}), 7.73(d, J=2.56 \mathrm{~Hz}, 1 \mathrm{H}), 7.66(d, J=2.48 \mathrm{~Hz}, 1 \mathrm{H})$, $7.45(b r, 1 \mathrm{H})$.

${ }^{13} \mathrm{C}$ NMR (400 MHz, $d_{6}$-DMSO, $298 \mathrm{~K}, \delta$ in p.p.m., Fig. S1b): 166.7, 157.4, 155.6, 153.2, 153.1, 144.4, 135.6, 133.5, 128.2, 126.8 and 125.8 .

FT-IR (KBr, $\mathrm{cm}^{-1}$, Fig. S2a): $3193.3(\mathrm{br}, \mathrm{OH}), 1677.8(\mathrm{~m}$, $\mathrm{C}=\mathrm{O}), 1612.7(m, \mathrm{C}=\mathrm{N}), 1555.6(w), 1498.6(w), 1451.7(m)$, $1434.1(w), 1349.4(w), 1180(m)$.

\subsection{Compound-B}

${ }^{1} \mathrm{H}$ NMR (400 MHz, $d_{6}$-DMSO, $298 \mathrm{~K}, \delta$ in p.p.m., Fig. S1c): $12.78(s, 1 \mathrm{H}), 12.53(s, 1 \mathrm{H}), 8.82(d, J=5.6 \mathrm{~Hz}, 2 \mathrm{H}), 8.56(s$, $1 \mathrm{H}), 7.85(t, J=2.8 \mathrm{~Hz}, 4 \mathrm{H})$.

${ }^{13} \mathrm{C}$ NMR (400 MHz, $d_{6}$-DMSO, $298 \mathrm{~K}, \delta$ in p.p.m., Fig. S1 $d$ ): 162.1, 154.1, 150.9, 148.5, 139.7, 136.3, 132.6, 122.0, 121.3, 111.8 and 111.7 .

FT-IR $\left(\mathrm{KBr}, \mathrm{cm}^{-1}\right.$, Fig. S2b): $3149.7(b r, \mathrm{OH}), 1685.3(\mathrm{~m}$, $\mathrm{C}=\mathrm{O}), 1593.9(m, \mathrm{C}=\mathrm{N}), 1549.5(w), 1441.8(w), 1370.3(m)$, $1340.1(w), 1269.1(w), 1218.7(m)$. 


\subsection{Compound-C}

${ }^{1} \mathrm{H}$ NMR (400 MHz, $d_{6}$-DMSO, $298 \mathrm{~K}, \delta$ in p.p.m., Fig. S1e): $12.76(s, 1 \mathrm{H}), 12.50(s, 1 \mathrm{H}), 8.83(d, J=6.0 \mathrm{~Hz}, 2 \mathrm{H}), 8.58(s$, $1 \mathrm{H}), 7.87(d, J=6 \mathrm{~Hz}, 2 \mathrm{H}), 7.78(d, J=3.2 \mathrm{~Hz}, 2 \mathrm{H})$.

${ }^{13} \mathrm{C}$ NMR (400 MHz, $d_{6}$-DMSO, $298 \mathrm{~K}, \delta$ in p.p.m., Fig. S1f): $166.8,158.5,155.6,153.3,144.4,138.5,134.5,128.6,126.7,125.4$ and 116.1 .

\subsection{Compound-D}

${ }^{1} \mathrm{H}$ NMR (400 MHz, $d_{6}$-DMSO, $298 \mathrm{~K}, \delta$ in p.p.m., Fig. S2g): $12.77(m, 2 \mathrm{H}), 8.83(m, 2 \mathrm{H}), 8.47(s, 1 \mathrm{H}), 8.08(d, J=1.2 \mathrm{~Hz}$, $1 \mathrm{H}), 7.95(s, 1 \mathrm{H}), 7.85(t, J=4.8 \mathrm{~Hz}, 2 \mathrm{H})$.

\subsection{Compound-E}

${ }^{1} \mathrm{H}$ NMR (400 MHz, $d_{6}$-DMSO, 298 K, $\delta$ in p.p.m., Fig. S2h): $12.46(s, 1 \mathrm{H}), 11.12(s, 1 \mathrm{H}), 8.81(d, J=4.8 \mathrm{~Hz}, 2 \mathrm{H}), 8.69(s$, $1 \mathrm{H}), 7.85(d, J=4.8 \mathrm{~Hz}, 2 \mathrm{H}), 7.39(m, 2 \mathrm{H})$.

\subsection{X-ray crystallography}

X-ray reflections for Compounds-A (Form I and Form II), B (Form I and Form II), -C (Form I), -D and -E were collected on a Bruker D8 Quest CCD diffractometer equipped with a graphite monochromator and an Mo $K \alpha$ fine-focus sealed tube $(\lambda=0.71073 \AA)$ at $298 \mathrm{~K}$. High-temperature data for Compound-A Form III and Compound-C Form II were collected on a Bruker D8 Venture diffractometer at 338 and $368 \mathrm{~K}$, respectively. Data reduction was performed using Bruker $A P E X 2$ software. Intensities were corrected for absorption using $S A D A B S$ (Sheldrick, 1997a) and the structures were solved and refined using SHELX97 (SMART 2000; Sheldrick, 1997b). All non-H atoms were refined anisotropically. $\mathrm{H}$ atoms on hetero atoms were located from difference electron-density maps and all $\mathrm{C}$-bound $\mathrm{H}$ atoms were fixed geometrically. ORTEP plots are shown in Fig. S3 in the supporting information. Hydrogen-bond geometries were determined using PLATON (Spek, 2002). X-Seed (Barbour, 1999) was used to prepare packing diagrams. The crystal structures have been deposited with the Cambridge Structural Database (CCDC Numbers 1548278-1548285). Compound-A Form $\mathrm{I}$ is reported in the CCDC as No. 824932.

\subsection{Powder X-ray diffraction (PXRD)}

Powder X-ray diffraction was recorded on Bruker D8 Advance diffractometer (Bruker AXS, Karlsruhe, Germany) using $\mathrm{Cu} K \alpha \mathrm{X}$-radiation $(\lambda=1.5406 \AA)$ at $40 \mathrm{kV}$ and $30 \mathrm{~mA}$ power. X-ray diffraction patterns were collected over the $2 \theta$ range $5-40^{\circ}$ at a scan rate of $1^{\circ} \mathrm{min}^{-1}$.

\subsection{Infrared spectroscopy (IR)}

A Nicolet 6700 FT-IR spectrometer with an NXR FTRaman Module was used to record IR spectra. IR spectra were recorded on samples dispersed in $\mathrm{KBr}$ pellets.

\subsection{Differential scanning calorimetry (DSC)}

DSC was performed on a Mettler Toledo DSC 822e module. Samples were placed in crimped but vented aluminium sample pans. The typical sample size was $3-5 \mathrm{mg}$. The temperature range was $303-573 \mathrm{~K}$ at $20 \mathrm{~K} \mathrm{~min}^{-1}$. Samples were purged by a stream of nitrogen flowing at $60 \mathrm{ml} \mathrm{min}^{-1}$.

\subsection{Thermogravimetric analysis (TGA)}

TGA was carried out using a Mettler Toledo TGASDTA 851e operating with $S T A R^{e}$ software to detect solvates and thermal degradation. Accurately weighed (5-15 mg) samples were loaded in alumina crucibles and heated at a rate of $20 \mathrm{~K} \mathrm{~min}^{-1}$ over a temperature range of 303 to $573 \mathrm{~K}$ under a nitrogen purge of $60 \mathrm{ml} \mathrm{min}{ }^{-1}$.

\subsection{Hot-stage microscopy (HSM)}

HSM was performed on a Wagner \& Munz Polytherm A Hot Stage and Heiztisch microscope. A Moticam 1000 (1.3 MP) camera supported by software Motic Image Plus 2.0ML was used to record images and videos (Fig. S4 in the supporting information).

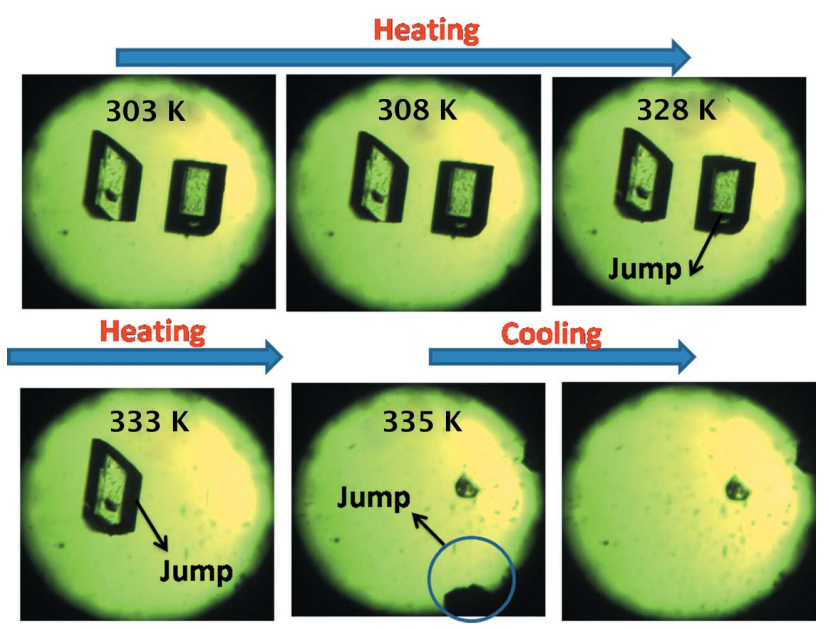

(a)

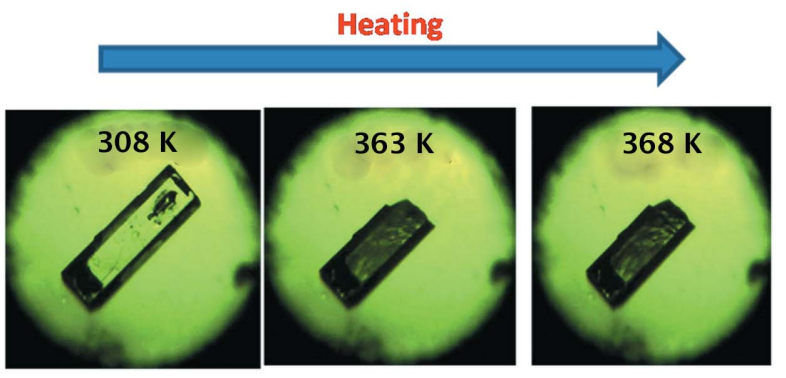

(b)

Figure 1

(a) HSM images of Compound-A Form I crystals during heating. (b) HSM images of Compound-C Form I crystals, and separation of debris during heating. 


\subsection{Computations}

The stabilization energies of all complexes were computed using M062X/6-31g(d,p) (SDD for Br and I) (Zhao \& Truhlar, 2008) in the GAUSSIAN09 package (Frisch et al., 2009). All energies are BSSE-corrected using the counterpoise method.

\section{Results and discussion}

The dichloro Compound-A was crystallized from methanol multiple times and finally provided diffraction-quality single crystals of Form I. Form II crystals were obtained from a methanol slurry after $1 \mathrm{~d}$. The high-temperature polymorph Form III was isolated by heating and it is stable at high temperature (above $330 \mathrm{~K}$, HT polymorph). Crystallization experiments on compounds- $\mathrm{B},-\mathrm{C},-\mathrm{D}$ and $-\mathrm{E}$ provided dimorphs of $\mathrm{B}$ and $\mathrm{C}$, while $\mathrm{D}$ and $\mathrm{E}$ each gave a single-crystal form. Scheme 2 shows the thermal-induced and crystallization transformation for polymorphs of Compound-A and Scheme 3 shows thermosalient (TS) effects on Compound-C. Preliminary observations of crystal changes were visualized on a hot-stage microscope (HSM). Upon heating Form I crystals of A to about $328-338 \mathrm{~K}$, a few crystals were seen to fly off suddenly from the hot stage to a few centimetres in height (1$2 \mathrm{~cm}$, Fig. 1a) and moved outside the camera zone, while other bits were fragmented into small pieces during heating. Form II crystals of A did not exhibit any thermal response. Crystals of B showed cracking upon heating (Fig. S4 $a$ in the supporting information) and Compound-C led to rapid breaking and separation of debris (Fig. 1b) at 363-368 K. Crystals of compounds-D and E were unresponsive to thermal stress.

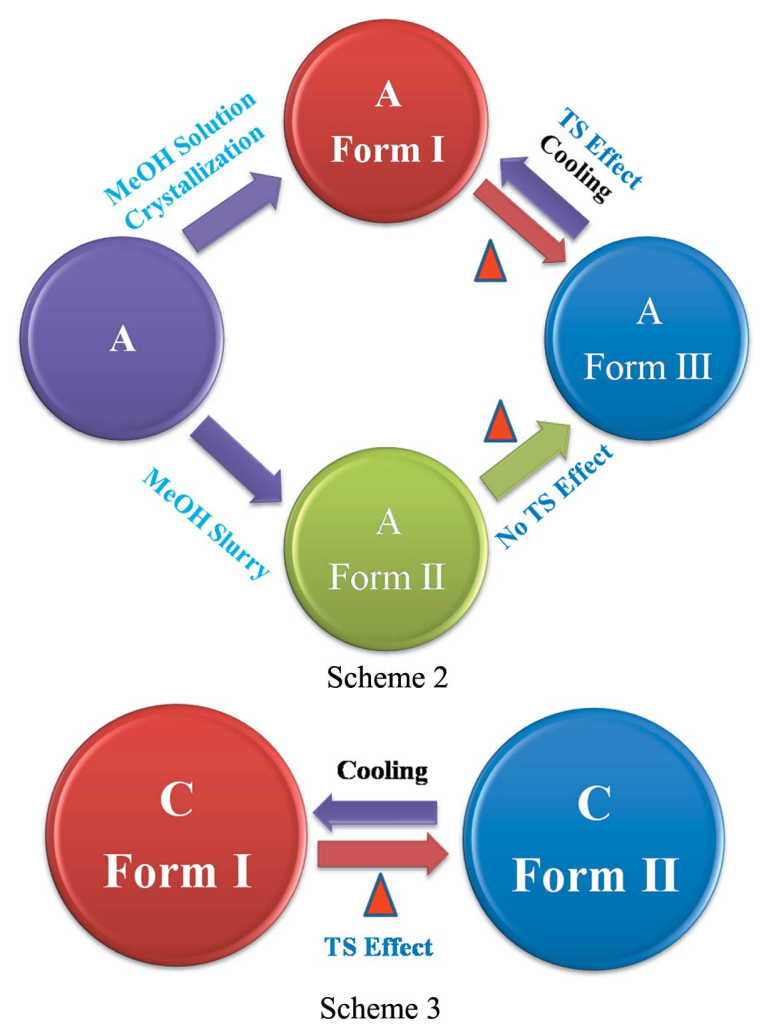

\subsection{X-ray crystal structures}

The X-ray crystal structures of Compound-A Form I and III were solved in the monoclinic space group $P 2_{1} / c$. The hydrazine $\mathrm{N}-\mathrm{H}$ bonds to the pyridine $\mathrm{N}$-acceptor $[\mathrm{N} 2-\mathrm{H} 2 B \cdots \mathrm{N} 3$ $=2.17$ (1) $\AA$ and $156(4)^{\circ}$ for Form I, and 2.23 (1) $\AA$ and $158.7(1)^{\circ}$ for Form III; Fig. $2 a$ ] to form a chain along the $b$ axis. Such chains extend through type II halogen bonds [Form I: $\mathrm{C}-\mathrm{Cl} \cdots \mathrm{Cl}-\mathrm{C}, \theta_{1}=155.44(5)^{\circ}, \theta_{2}=95.96(5)^{\circ}$; Form III: $\theta_{1}$ $=155.5(4)^{\circ}, \theta_{2}=95.2(3)^{\circ}$; Fig. 2b] (Metrangolo \& Resnati, 2014; Mukherjee \& Desiraju, 2014). An intramolecular hydrogen bond is present between the imine $\mathrm{N}$ atom and the phenolic $\mathrm{H}$ atom $\left[\mathrm{O} 2-\mathrm{H} 2 A \cdots \mathrm{N} 1=1.86(2) \AA\right.$ and $145^{\circ}$ and 1.88 (1) $\AA$ and 144.1 (4) $)^{\circ}$ for Forms I and III, respectively, forming an $S(6)$ ring motif. In the case of Form II, crystals were obtained by fast evaporation of solvent from the solution and the structure was solved and refined in orthorhombic space group $P c a 2_{1}$ with one molecule in the asymmetric unit. Similar to Form I, Form II also has the same type of one-

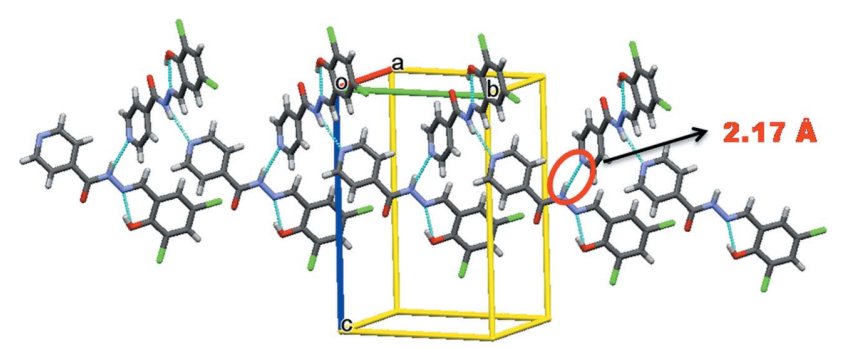

(a)

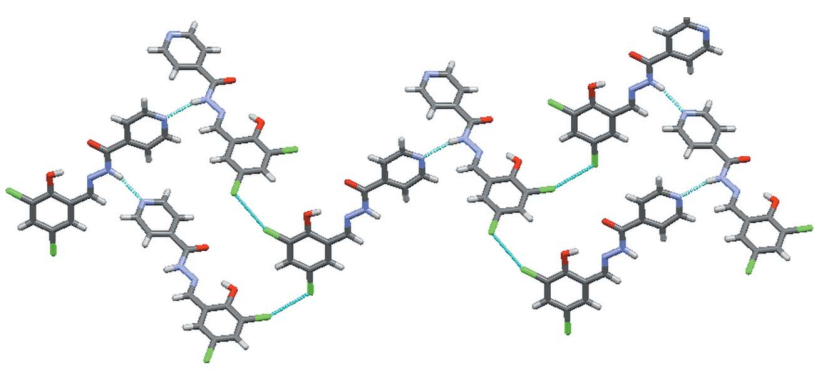

(b)
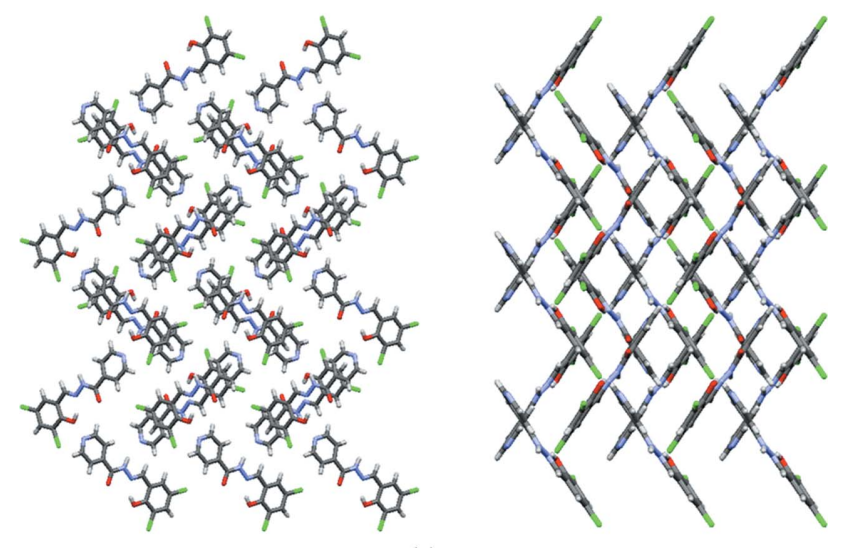

(c)

Figure 2

(a) The one-dimensional chain of Form I of Compound-A propagating through the $\mathrm{N}-\mathrm{H} \cdots \mathrm{N}$ (pyridine) synthon. (b) Type II halogen bonding. (c) Packing of molecules along the $a$ and $c$ axes (Form I). 


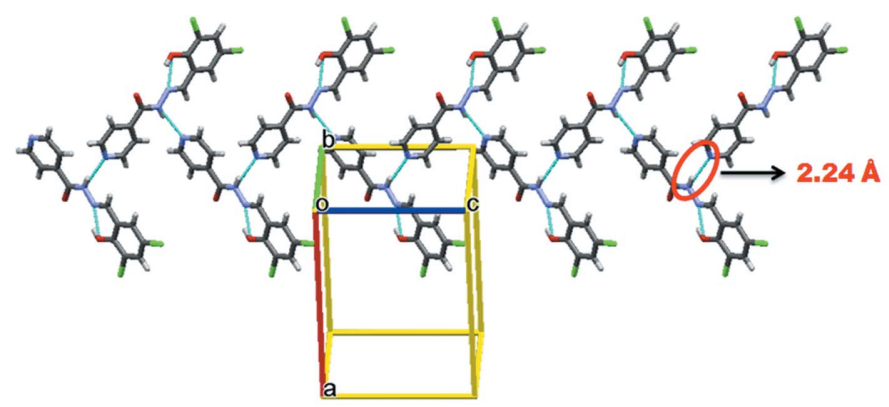

(a)
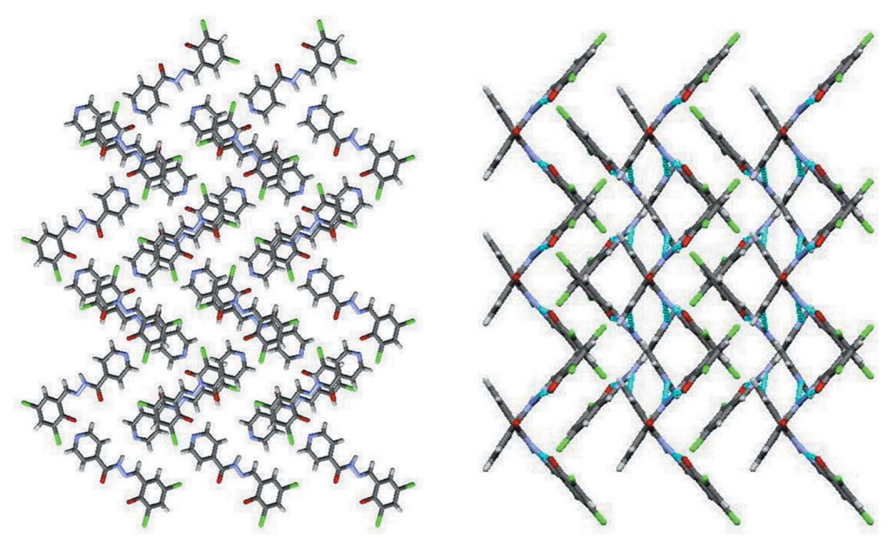

(c)
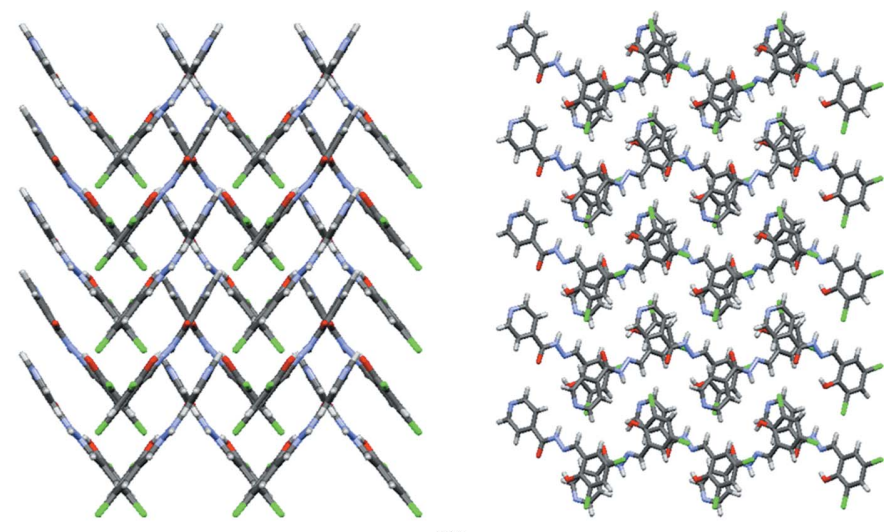

(b)

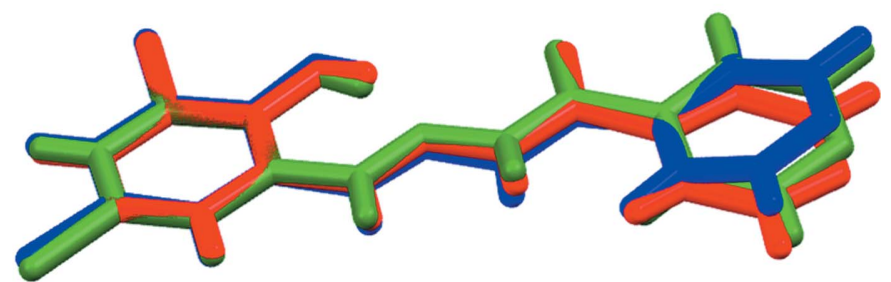

$(d)$

Figure 3

(a) The one-dimensional chain of Form II of Compound-A propagating through the $\mathrm{N}-\mathrm{H} \cdots \mathrm{N}$ (pyridine) synthon. (b) Packing of molecules along the $a$ and $b$ axes (Form II). (c) Packing of molecules along the $a$ and $c$ axes (Form III). (d) Overlay of the Form I (green), Form II (blue) and Form III (red, high-temperature polymorph) crystal structures (Compound-A).

dimensional chains (Fig. $3 a$ ) and the chain grows parallel to the $c$ axis. The one-dimensional chains are extended by type II $\left[\mathrm{C}-\mathrm{Cl} \cdots \mathrm{Cl}-\mathrm{C}, \theta_{1}=151.2(1)^{\circ}, \theta_{2}=100.21(8)^{\circ}\right]$ halogen-bonding interactions (Saha et al., 2006). Similar to Forms I and III, Form II also reveals the same types of hydrogen- and halogen-bonding interactions except for changes in the halogen/hydrogen-bonding distances (Table 1).

Compound-B Form I crystallized from methanol solvent and was solved in the monoclinic crystal system, space group $P 2_{1} / c$, with one molecule in the asymmetric unit. Similar to Form I of the dichloro derivative, the hydrazine $\mathrm{H}$ atom interacts with the pyridine $\mathrm{N}$ atom through an $\mathrm{N} 2-\mathrm{H} 2 B \cdots \mathrm{N} 3$ hydrogen bond $\left[2.13(2) \AA\right.$ and $\left.152.4(1)^{\circ}\right]$, forming a onedimensional chain (Fig. 4a). These chains grow parallel to the $b$ axis and are extended by type II halogen bonds [C$\mathrm{Br} \cdots \mathrm{Br}-\mathrm{C}, \theta_{1}=166.0(1)^{\circ}, \theta_{2}=94.4(1)^{\circ}$ Fig. $\left.4 b\right]$. Form II was obtained by heating Form I crystals. It crystallized in the triclinic space group $P \overline{1}$ with two molecules in the asymmetric unit. A tetrameric ring motif is formed through $\mathrm{N} 2-$ $\mathrm{H} 2 B \cdots \mathrm{O} 3\left[2.15(1) \AA\right.$ and $\left.164.2(1)^{\circ}\right]$ and $\mathrm{N} 5-\mathrm{H} 5 B \cdots \mathrm{O} 1$ [2.11 (1) $\AA$ and $168.9(1)^{\circ}$; Fig. 4c] hydrogen-bonding interactions, forming an $R_{4}^{4}(16)$ motif. The tetrameric rings are extended by type $\mathrm{I}$ halogen bonds $\left[\mathrm{C}-\mathrm{Br} \cdots \mathrm{Br}-\mathrm{C}, \theta_{1}=\theta_{2}=\right.$ $\left.142.6(2)^{\circ}\right]$. There are significant differences in the dihedral angles between the two rings before [Form I, ring atom numbers $\mathrm{C} 1-\mathrm{C} 6$ and $\left.\mathrm{C} 9-\mathrm{C} 13 / \mathrm{N} 315.55(3)^{\circ}\right]$ and after phase transformation [Form II, ring atom numbers $\mathrm{C} 14-\mathrm{C} 19$ and $\mathrm{C} 22-\mathrm{C} 26 / \mathrm{N} 641.36(3)^{\circ}$, and ring atom numbers $\mathrm{C} 1-\mathrm{C} 6$ and C9-C13/N3 $4.47(4)^{\circ}$; Table 2].

Table 1

Selected halogen- and hydrogen-bond distances in all nine polymorphic structures.

\begin{tabular}{llll}
\hline Compound & Polymorph & $X \cdots X(\AA)$ & $\mathrm{N}-\mathrm{H} \cdots \mathrm{N}(\AA)$ \\
\hline Compound-A & Forms I, II, III & $3.435(6), 3.395(1), 3.448(4)$ & $2.17(1), 2.24(2), 2.23(1)$ \\
Compound-B & Forms I, II & $3.587(1), 3.415(1)$ & $2.13(2)$ \\
Compound-C & Forms I, II & $3.4962(9), 3.50(1)$ & $2.16(3), 2.22(3)$ \\
Compound-D & & $3.8561(5)$ & $2.15(5)$ \\
Compound-E & & & $2.19(1)$ \\
\hline
\end{tabular}


Table 2

Dihedral angles between the two rings $\mathrm{C} 1-\mathrm{C} 6$ and $\mathrm{C} 9-\mathrm{C} 13 / \mathrm{N} 3$.

\begin{tabular}{ll}
\hline Compound & Dihedral angle $\left({ }^{\circ}\right)$ \\
\hline Compound-A Forms I, II and III & $10.26(8), 9.76(1)$ and $10.95(6)$ \\
Compound-B Form I & $15.55(3)$ \\
Compound-B Form II & $41.36(3) \dagger$ and $4.47(4)$ \\
Compound-C Forms I, II & $12.05(2), 10.54(3)$ \\
Compound-D & $19.72(2)$ \\
Compound-E & $5.34(2)$ \\
\hline
\end{tabular}

$\dagger$ In Compound-B Form II, the dihedral angle of $41.36^{\circ}$ is between the rings C14-C19 and $\mathrm{C} 22-\mathrm{C} 26 / \mathrm{N} 6$.

Similar to the above two compounds, Compound-C (Forms I and II) also has the same types of hydrogen- and halogenbonding interactions: $\mathrm{N} 2-\mathrm{H} 2 B \cdots \mathrm{N} 3\left[2.16(3) \AA\right.$ and $156(2)^{\circ}$, and $2.22(3) \AA$ and $\left.156(3)^{\circ}\right]$ in a one-dimensional chain (Fig. $5 a$ ) and type II [Form I, C-Cl $\cdots \mathrm{Br}-\mathrm{C}, \theta_{1}=167.48(8)^{\circ}, \theta_{2}=$ $98.49(9)^{\circ}$; Form II, C-Cl $\cdots \mathrm{Br}-\mathrm{C}, \theta_{1}=163.1(1)^{\circ}, \theta_{2}=$ $97.9(1)^{\circ}$; Fig. $\left.5 b\right]$ halogen bonds between the chains.

In the crystal structure of Compound-D, dimers are formed through $\mathrm{C}-\mathrm{I} \cdots \mathrm{O}$ halogen-bonding interactions and these dimers are extended via type II halogen bonds [C-I $\cdots \mathrm{I}-\mathrm{C}$, $3.856 \AA$ and $\theta_{1}=170.3(1)^{\circ}, \theta_{2}=91.95(9)^{\circ}$; Fig. $\left.6 a\right]$ and $\mathrm{N} 2-$ $\mathrm{H} 2 B \cdots \mathrm{N} 3\left[2.15(5) \AA\right.$ and $146(5)^{\circ}$; Fig. 6b) hydrogenbonding interactions.

Similar to the above structures, in Compound-E the same type of $\mathrm{N} 2-\mathrm{H} 2 B \cdots \mathrm{N} 3$ hydrogen bonds are present (Fig. S5 in the supporting information) but halogen bonding is absent for the fluoro group, which does not generally engage in intermolecular interactions (Dikundwar et al., 2014; Chopra \& Row, 2011).

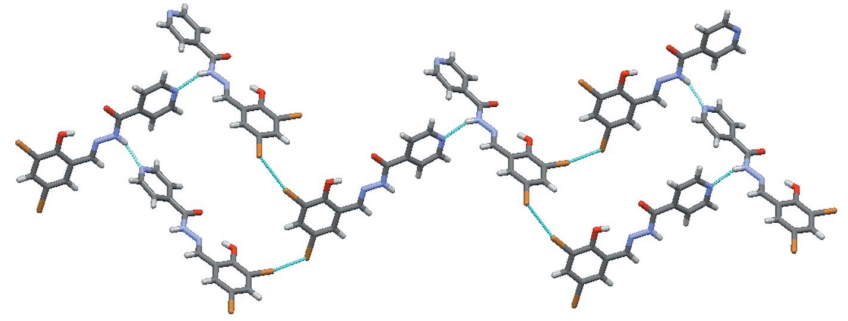

(a)

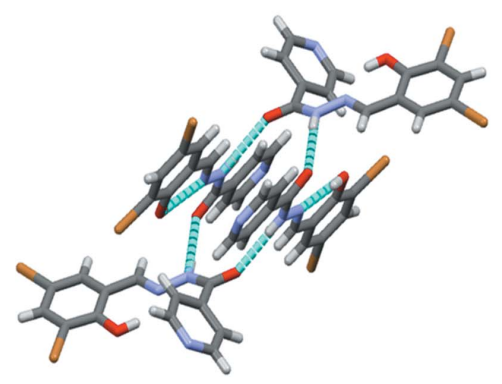

(c)

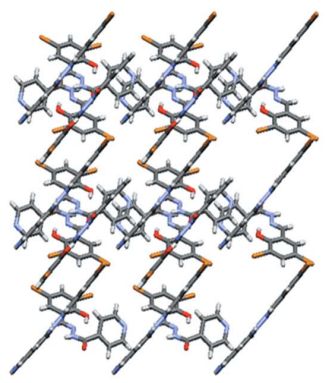

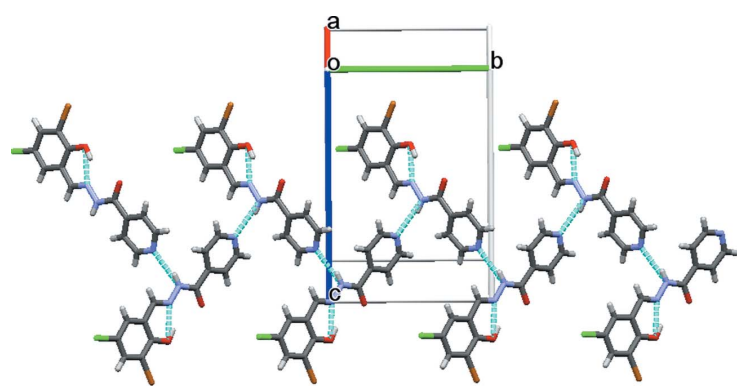

(a)

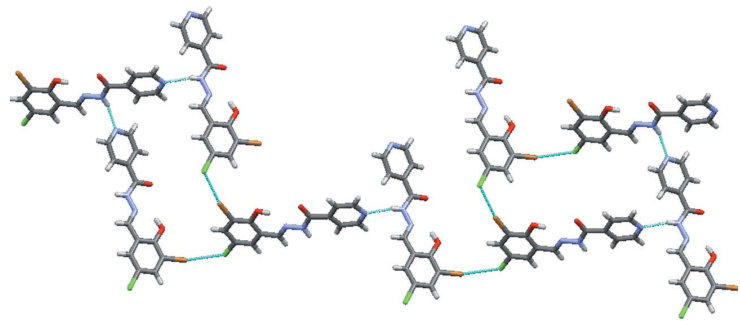

(b)

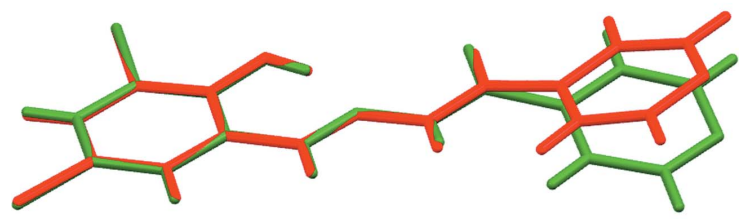

(c)

Figure 5

(a) The one-dimensional chain propagating through the $\mathrm{N}-\mathrm{H} \cdots \mathrm{N}$ (amino-pyridine) synthon (Form I, Compound-C). (b) Cl $\cdots$ Br type II halogen-bonding interactions. (c) Overlay of Form I (green) and Form II (red) molecules.
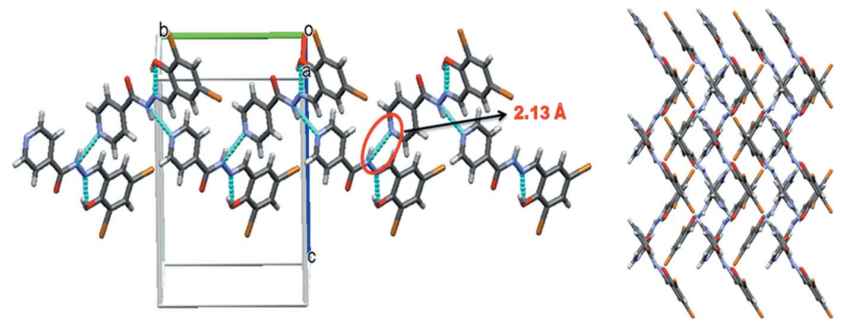

(b)

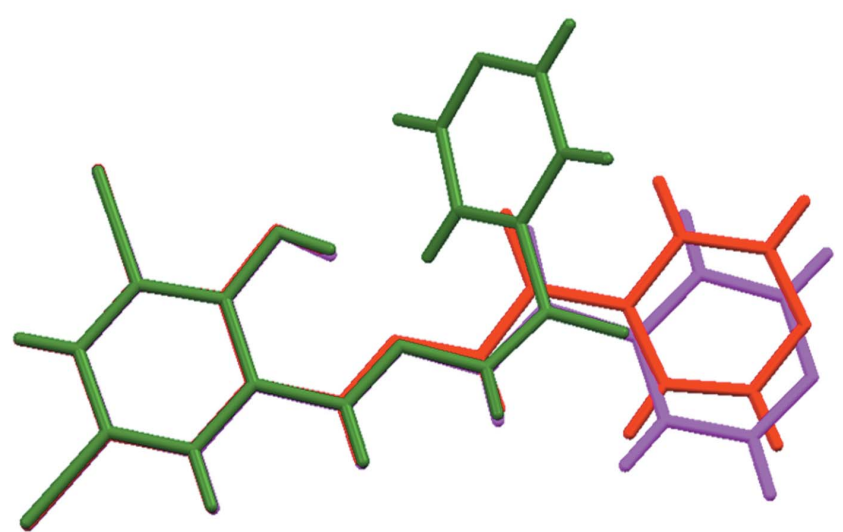

$(d)$

Figure 4

(a) Type II halogen-bonding interactions of Compound-B. (b) The one-dimensional chain propagating through the $\mathrm{N}-\mathrm{H} \cdots \mathrm{N}$ (pyridine) synthon (Form I) and packing of molecules along the $c$ axis. (c) The tetrameric ring motif (Form II) and packing diagram (along the $c$ axis). (d) Overlay of Form I (red) and Form II (green and magenta) of Compound-B. 


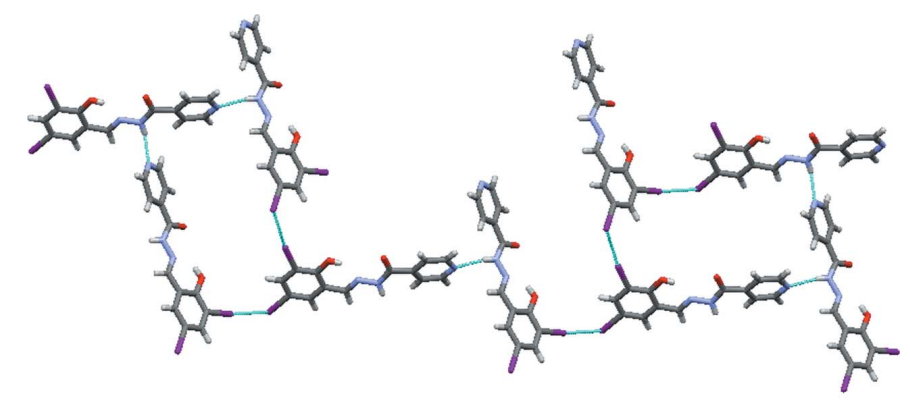

(a)

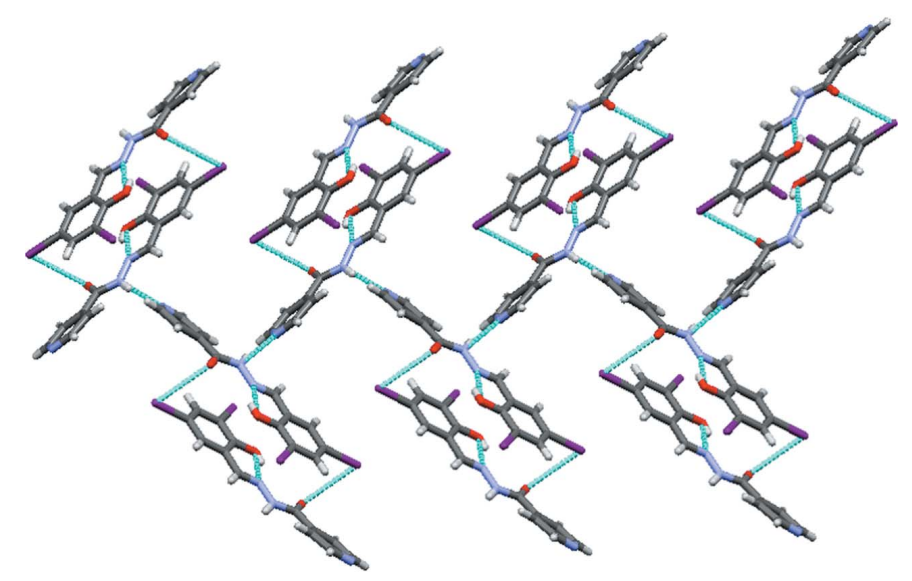

(b)

Figure 6

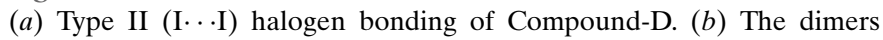
extended via $\mathrm{N}-\mathrm{H} \cdots \mathrm{N}$ hydrogen bonds (Compound-D).

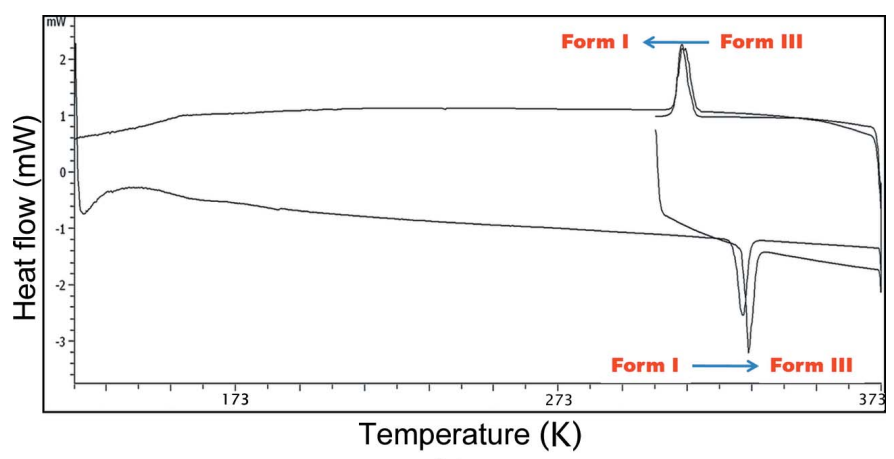

(a)

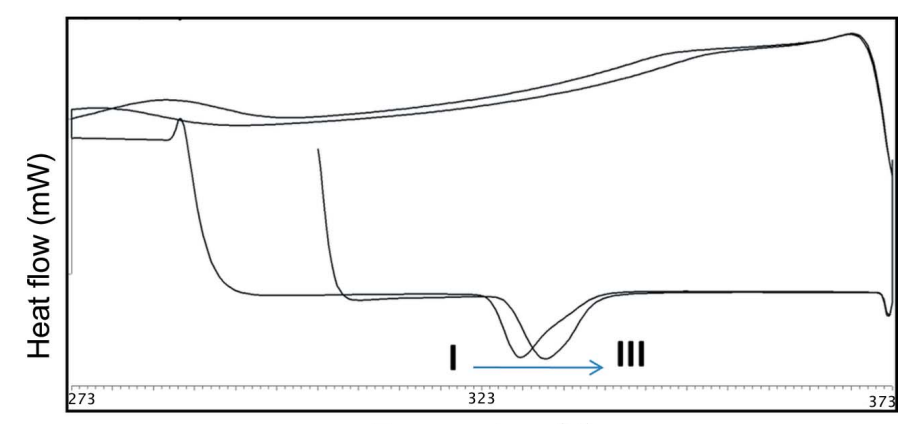

Temperature (K)

(b)

Figure 7

(a) DSC thermogram of Compound-A Form I crystals (heat-coolreheat). (b) DSC thermogram of Compound-A Form I ground material (heat-cool-reheat).

\subsection{VT-PXRD and thermal analysis}

In order to understand the events observed on the hot-stage microscope, both DSC and variable-temperature PXRD were performed on all the materials. Heating Compound-A, Form I showed an endotherm at $330.4 \mathrm{~K}$, indicating the transformation of Form I to Form III (Nauha \& Bernstein, 2014). Cooling the same material exhibited an exotherm at $308-318 \mathrm{~K}$, indicating Form III $\rightarrow$ Form I conversion. Reheating the same material showed an endotherm at $328.4 \mathrm{~K}$ (Form I $\rightarrow$ Form III) followed by melting at $523.9 \mathrm{~K}$ (Fig. $7 a$, and Fig. S6 $a$ in the supporting information). These observations suggest that Forms I and III are enantiotropic polymorphs and that Form III is stable after the phase transition (high-temperature polymorph, VT-PXRD plots in Fig. 6b). In the case of Form II (Compound-A) an endotherm was observed at $513.3 \mathrm{~K}$ after Form II converted into Form III. On cooling the same solid, Form III transformed into Form I and showed an exotherm at 278-293 K. On reheating the same material, an endotherm was observed at $323.8 \mathrm{~K}$ followed by melting at $523.3 \mathrm{~K}$ (Fig. 8). Apart from heating, competitive slurry experiments (in solution medium, methanol as solvent) suggest that Form II is more stable than Form I. Heating Compound-B showed a small endotherm at $486.1 \mathrm{~K}$ and a second endotherm at 492.6 K, which indicates the transformation of Form I into Form II, followed by melting at $519.3 \mathrm{~K}$ (Fig. 9). This means that Forms I and II are enantiotropically related.

In case of Compound- $\mathrm{C}$, an endotherm was observed at $364.4 \mathrm{~K}$ for the conversion of Form I to Form II. Cooling the same material showed an exotherm at $343-353 \mathrm{~K}$ for the conversion of Form II to Form I, and on reheating of the material an endotherm was observed at $362.7 \mathrm{~K}$ followed by melting at $528.5 \mathrm{~K}$ (Fig. $10 a$, and Fig. S7a in the supporting information). The transformation of Form I and Form II is reversible and Form II is stable at high temperature (above $393 \mathrm{~K}$, Fig. S7b). Compounds-D and E melted at 518 and $560 \mathrm{~K}$, respectively, without any phase transformation, indicating the absence of polymorphism in these two compounds (Figs. S8 and S9). DSC of the ground material (Figs. $7 b$ and $10 b)$ showed the same type of reversible phase transitions, wherein the intensity of the peaks was less than those of the single-crystal material thermal profile, indicating that single crystals can withstand the pressure which is accumulated during heating and the release of strain compared with the powder solids. The crystalline materials undergo phase transitions in a very short time (microseconds) and this sudden change is the probable reason for the thermosalient effect. All the observed changes were verified by HSM, DSC and VTPXRD (Figs. S4, S6, S7, S8, S9 in the supporting information). All experiments were performed multiple times to confirm reproducibility.

\subsection{Powder X-ray analysis}

Powder XRD is a nondestructive technique and most useful for the identification of different powder materials. Signature lines for Compound-A (Form I) were observed at 2 $\theta$ 9.9, 10.9, 14.0, 14.7; Form II at 10.6, 12.0, 14.1, 16.7 and Form III at 10.3, 


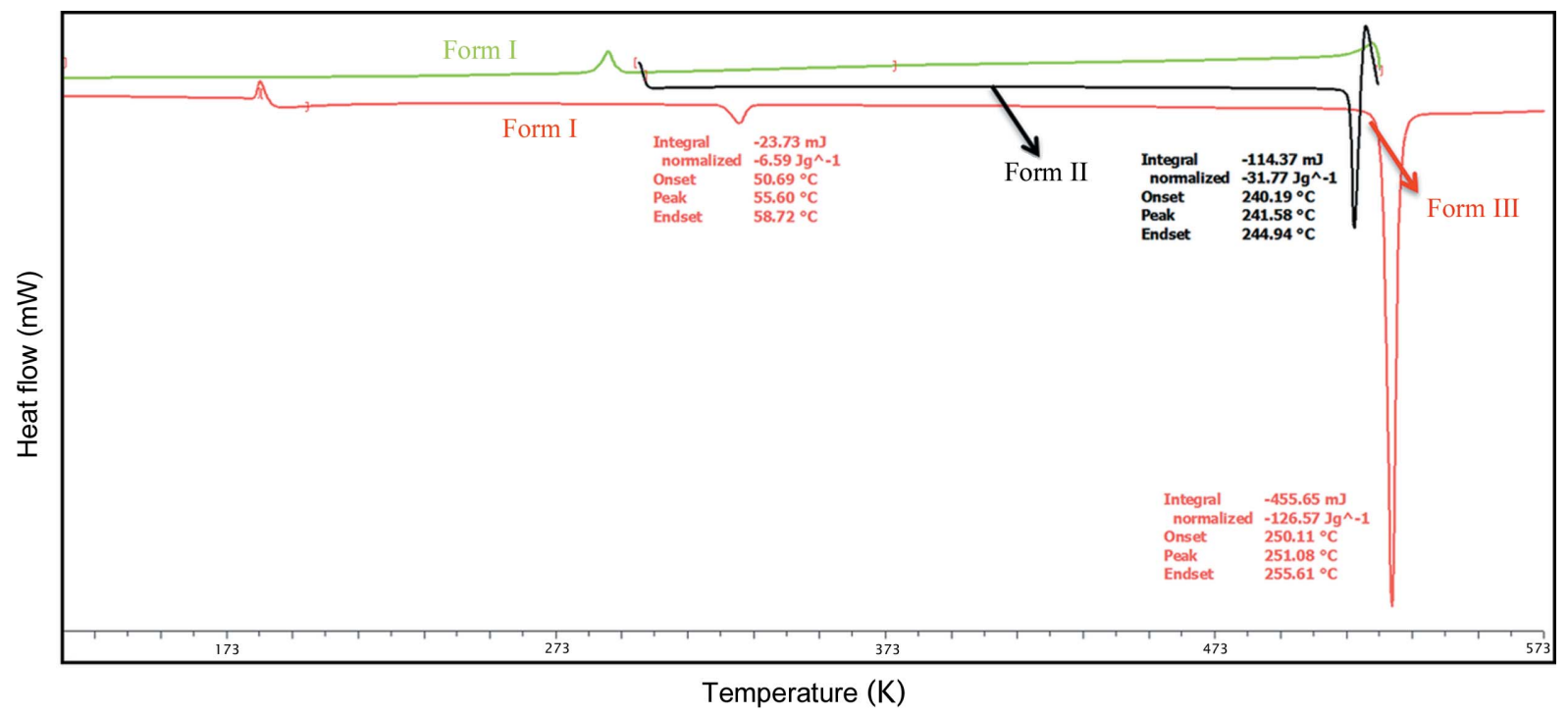

Figure 8

DSC thermogram of Compound-A Form II (heat-cool-reheat).

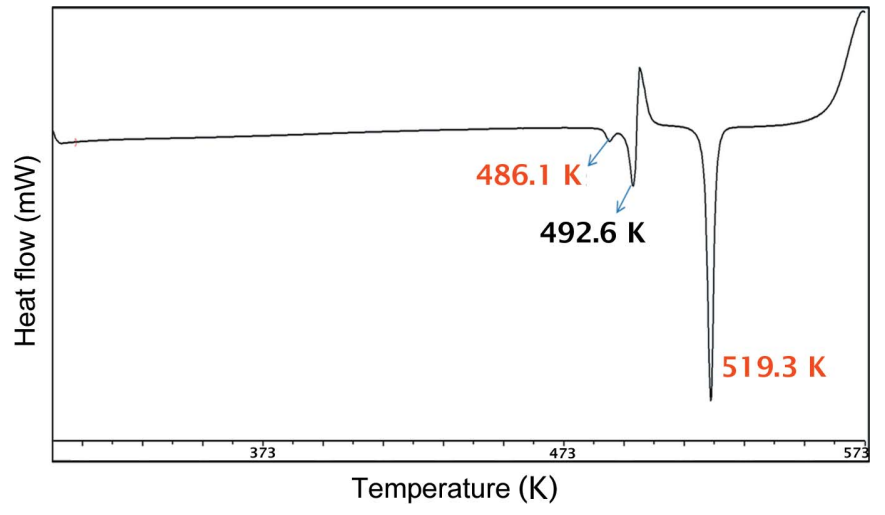

Figure 9

DSC thermogram of Compound-B Form I.

13.3, 14.3, 17.6; Compound-B Form I at 9.8, 11.3, 12.6, 15.0; Form II at 8.4, 9.0, 13.1, 18.0; Compound-C Form I at 9.9, 10.7, 13.9, 15.1; Form II at 10.2, 14.1, 17.8, 19.0 (Fig. S10).

\subsection{Thermomechanical effect and role of halogen bonding}

Different thermal events (jumping/separation of debris, and cracking; Fig. 11a) were observed in halogen derivatives such as Compounds- $\mathrm{A}$, - $\mathrm{B}$, and $-\mathrm{C}$ even though they are isomorphous (Table 3) and three-dimensionally isostructural (XPac

Table 3

Unit-cell similarity index (П).

\begin{tabular}{ll}
\hline Compound & Unit cell similarity index $(\Pi)$ \\
\hline Compounds-A and -B & 0.0139 \\
Compounds-B and -C & 0.0020 \\
Compounds-C and -D & 0.0246 \\
Compounds-D and -E & 0.0735 \\
Compounds-A and -D & 0.0362 \\
Compounds-A and -E & 0.0344 \\
\hline
\end{tabular}

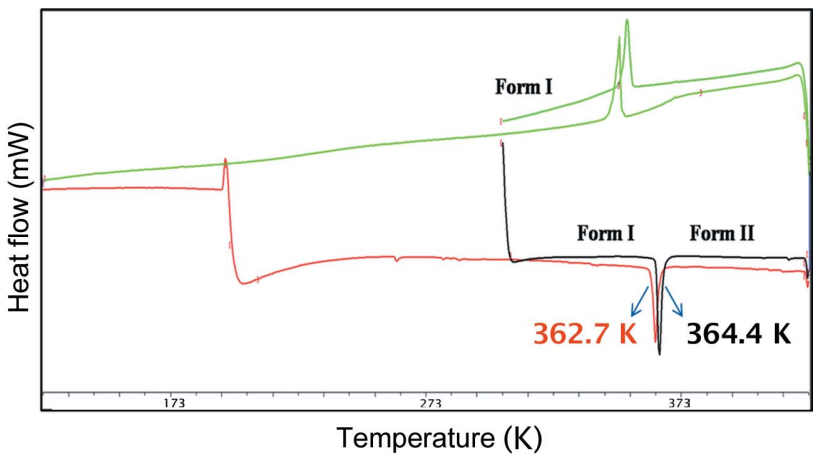

(a)

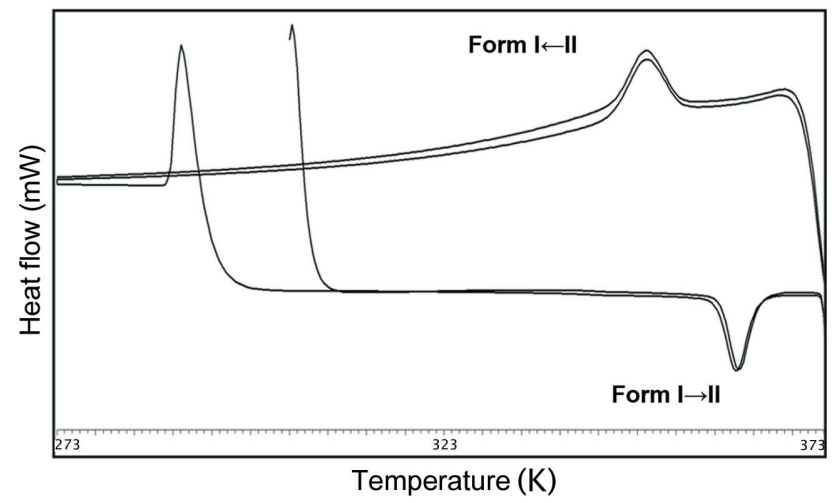

(b)

Figure 10

(a) DSC thermogram of Compound-C Form I (heat-cool-reheat). (b) DSC thermogram of Compound-C Form I ground material (heat-coolreheat).

analysis; Fig. S11; Gelbrich et al., 2012) and have the same type of hydrogen/halogen-bonding interactions and similar packing (Fig. 12), except for the change of halogen atom. During heating of Compound-A, jumping/explosion of crystals later converted into fine powder, Compounds-B and $\mathrm{C}$ showed breaking and cracking of the crystal into pieces during the 


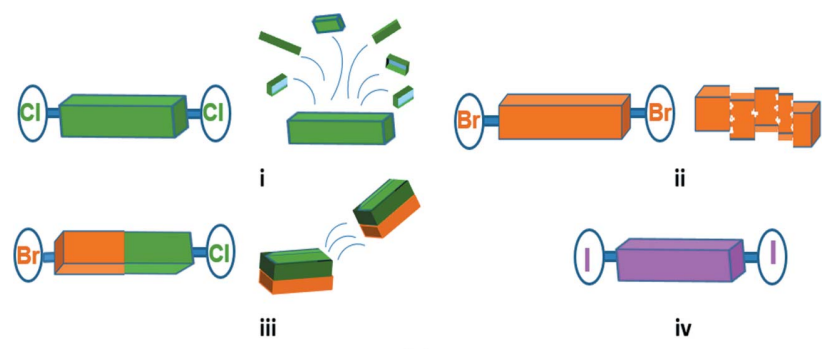

(a)

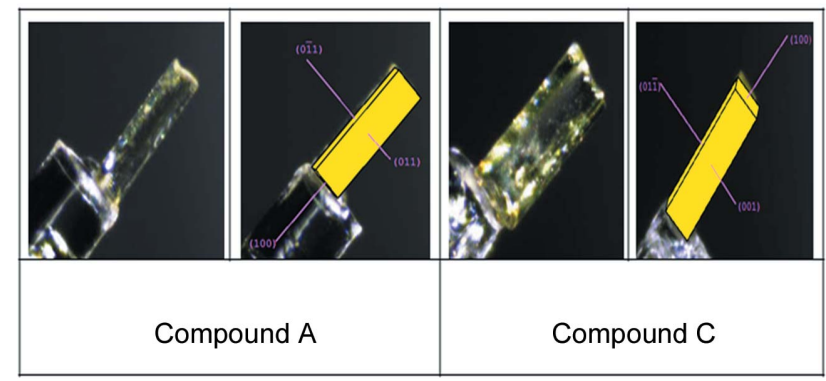

Figure 11

(b)

(a) Thermosalient effects of crystals, such as (i) jumping/explosion, (ii) cracking and (iii) rapid breaking of a crystal into two pieces during the phase transition. (iv) The iodine derivative crystal is intact upon heating. (b) Morphology and faces of Form I crystals of Compounds-A and C.

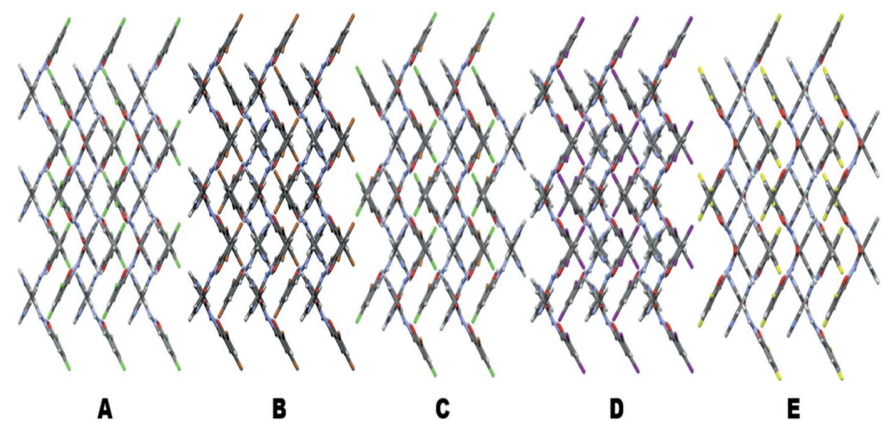

Figure 12

Packing of molecules in the halogen derivatives $\mathrm{A}$ to $\mathrm{E}$ to show the similarity.

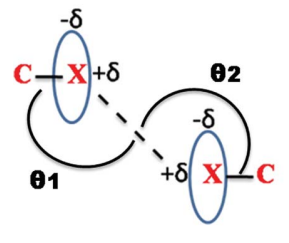

Type-I

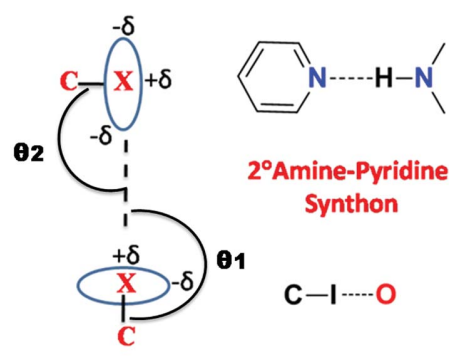

Type-II
Halogen/Hydrogen Bonding Interactions

Figure 13

Halogen-bonding interactions and hydrogen-bonding synthons in the present study.

phase transition, and no effect was observed in Compounds-D and E. In the present study, all compounds except B (Form II) contain type II halogen-bonding interactions, i.e. those with an
Table 4

Strength of halogen bonds $\dagger$.

\begin{tabular}{lll}
\hline Compound & $\begin{array}{l}\text { Halogen } \\
\text { bond } \\
(X \cdots X)\end{array}$ & $\begin{array}{l}\text { Stabilization } \\
\text { energy } \\
\left(\mathrm{kcal} \mathrm{mol}^{-1}\right)\end{array}$ \\
\hline Compound-A (Forms I and II) & $\mathrm{Cl} \cdots \mathrm{Cl}$ & $-4.18,-5.31$ \\
Compound-B (Form I) & $\mathrm{Br} \cdots \mathrm{Br}$ & -4.39 \\
Compound-C (Form I) & $\mathrm{Cl} \cdots \mathrm{Br}$ & -4.24 \\
Compound-D & $\mathrm{I} \cdots \mathrm{I}$ & -4.70 \\
\hline
\end{tabular}

$\dagger$ See Table S3 in the supporting information for full details.

attractive $\delta^{+} \cdots \delta^{-}$polarization (Metrangolo \& Resnati, 2014; Mukherjee \& Desiraju, 2014). Type II interactions are strong and attractive in nature (Bui et al., 2009). Due to the anisotropic distribution of electrons on the heavier halogen atoms, a partial positive charge develops opposite to the sigma bond ( $\sigma$ hole) and a partial negative charge in the equatorial region, leading to an attractive $\delta^{+} \cdots \delta^{-}$interaction (Fig. 13). The exception is the fluorine atom (Thalladi et al., 1998) which is hard, highly electronegative and non-polarizable. On moving from chlorine to iodine, the polar flattening of the halogen atom increases due to the decrease in electronegativity and the increase in polarizability, thereby resulting in a stronger type II inter-halogen bond (Desiraju \& Parthasarathy, 1989). The electrostatic nature of type II halogen bonding (Metrangolo \& Resnati, 2014; Mukherjee \& Desiraju, 2014) means that crystal structures containing these interactions are more responsive to temperature changes (thermosalient effects). Saraswatula \& Saha (2014) reported that thermal expansion of inter-halogen distances is higher for lower halogens (chlorine) and a decrease in expansion was observed with an increase in the halogen-bond strength. So the behaviour of heavier halogen atom-containing species is different from that of the lower halogens. Fluorine is an exception to showing halogen bonding due to its high electronegativity. In effect, the stronger halogen-bonded structures (Table 4) with $\mathrm{Br}$ and $\mathrm{I}$ atoms make them less responsive to temperature and mechanical stress because the halogen bond is too strong for the heavier halogens to show structural dynamics and mechanical property effects. The decreasing order of thermal response for inter-halogen interactions is $\mathrm{Cl} \cdots \mathrm{Cl}>\mathrm{Cl} \cdots \mathrm{Br}>$ $\mathrm{Br} \cdots \mathrm{Br}>\mathrm{I} \cdots \mathrm{I}$, indicating the importance of weaker $\mathrm{Cl} \cdots \mathrm{Cl}$ interactions in exhibiting a mechanical response of molecular crystals and temperature effects.

Heating the crystals of Compound-A Form I in the (011)/ $(01 \overline{1})$ (Fig. 11b) faces resulted in a thermal response of the crystals, some of which were seen to fly off the hot stage while a few others exploded into pieces at $330 \mathrm{~K}$. They converted into metastable Form III, with an increase in cell parameters along the $a$ axis (7.7\%) and a decrease in the $b$ and $c$ axes $(4.5$ and $0.8 \%$, respectively) and an increase in volume (of $2.1 \%$, Table 5). During cooling the crystals moved without any disintegration. Heat-cool cycles were conducted 3-4 times, after which the crystals exhibiting a thermal response turned to powder. Similarly, Form II also converted into Form III at $513 \mathrm{~K}$ without any thermal response. Comparison of the two crystal structures (Forms I and II) showed changes in the 
Table 5

Cell parameters and phase transitions of the polymorphs.

\begin{tabular}{|c|c|c|c|c|c|c|}
\hline Transition & $T(\mathrm{~K}) \mathrm{DSC}$ & Form & $a$ axis $(\AA)$ & $b$ axis $(\AA)$ & $c$ axis $(\AA)$ & Volume $\left(\AA^{3}\right)$ \\
\hline Compound-A & $298-326$ & $\mathrm{I} \dagger$ & $8.0683(4)$ & $10.7464(6)$ & $15.6155(8)$ & $1353.78(12)$ \\
\hline \multirow[t]{2}{*}{$\mathrm{I} \rightarrow \mathrm{III}$} & $330-332$ & $\mathrm{III} \ddagger$ & $8.6916(6)$ & $10.2641(7)$ & $15.4965(10)$ & $1382.46(16)$ \\
\hline & & Difference (\%) & 7.72 & -4.48 & -0.76 & 2.11 \\
\hline \multirow{2}{*}{$\mathrm{I} \rightarrow \mathrm{II}$} & & $\mathrm{II} \dagger$ & $9.8084(7)$ & $10.7751(8)$ & $13.9516(9)$ & $1429.11(17)$ \\
\hline & & Difference (\%) & 18.65 & -1.29 & -11.33 & 1.16 \\
\hline Compound-C & $298-358$ & $\mathrm{I} \dagger$ & $8.2475(9)$ & $10.8035(11)$ & $15.7971(15)$ & $1399.6(2)$ \\
\hline $\mathrm{I} \rightarrow \mathrm{II}$ & $360-366$ & II§ & $8.651(2)$ & $10.446(3)$ & $15.680(4)$ & $1413.3(7)$ \\
\hline
\end{tabular}

$\dagger$ Unit cell measured at $298 \mathrm{~K} . \$$ Unit cell measured at $338 \mathrm{~K} . \quad \S$ Unit cell measured at $368 \mathrm{~K}$.

hydrogen-bond distances and packing of the molecules. In a Hirshfeld analysis (Fig. 14, and Fig. S12), Form II has a greater contribution from $\mathrm{Cl} \cdots \mathrm{H}, \mathrm{O} \cdots \mathrm{H}, \mathrm{N} \cdots \mathrm{H}$ and $\mathrm{Cl} \cdots \mathrm{Cl}$ contacts $(47.3 \%)$ compared with Form I $(45.7 \%)$, and the halogenbond distances are shorter (stronger bonding) in Form II compared with Form I (Tables 1, 4), thus supporting the nonthermosalient transformation of Form II to Form III.

On heating crystals of Compound-B Form I on the $(0 \overline{11}) /$ (011) faces (Fig. S13), Form I transformed to Form II with cracking, with an increase in $Z^{\prime}$ from 1 to 2 and a lengthening of the $a$ axis $(18.7 \%)$ and a decrease in the $b$ and $c$ axes $(1.3$ and $11.3 \%$, respectively), but with a negligible increase in the overall cell volume (1.2\%).

Rapid breaking of the crystals was observed during heating of Compound-C Form I crystals on the $(0 \overline{1} 1) /(01 \overline{1})$ faces (Fig.
$11 b)$, with an expansion on the $a$ axis and contraction along the $b$ and $c$ axes.

To understand the thermal response of these molecular crystals, the room-temperature and high-temperature polymorphic structures of Compounds- $\mathrm{A},-\mathrm{B}$ and $-\mathrm{C}$ were compared. The integrity of the hydrogen-bonding interactions is retained in the structures of Compounds-A (Form I $\rightarrow$ Form III) and C (Form I $\rightarrow$ Form II) without any significant changes in dihedral angles (Table 2), hydrogen- and halogen-bond distances or packing of the molecules, before and after the phase transition (Table 1). However, in the case of Compound-A Form II $\rightarrow$ Form III and Compound-B Form I $\rightarrow$ Form II, the transition occurs with significant changes in hydrogen- and halogen-bonding interactions and in the packing of the molecules. A probable reason for the thermal
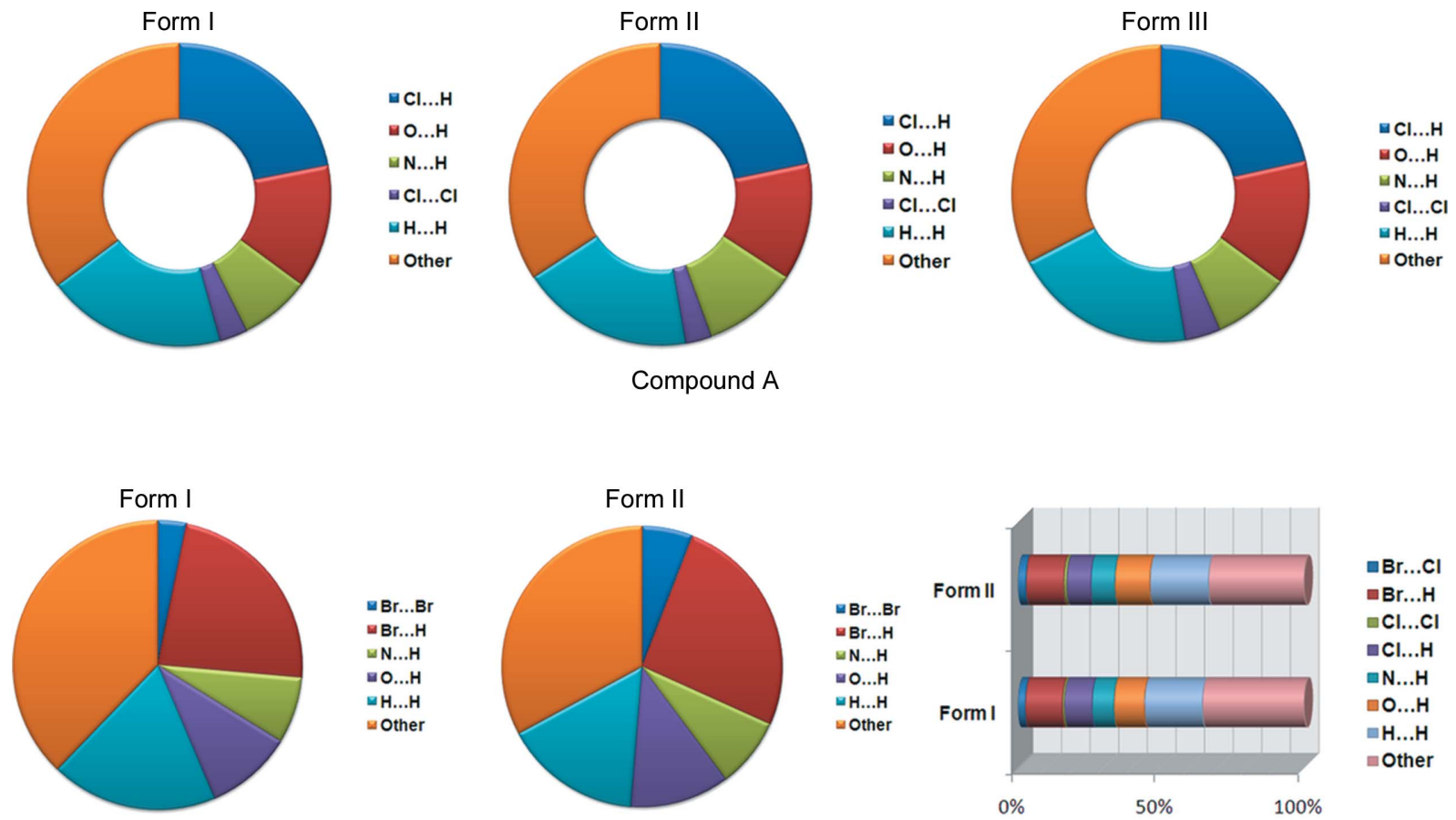

Compound B

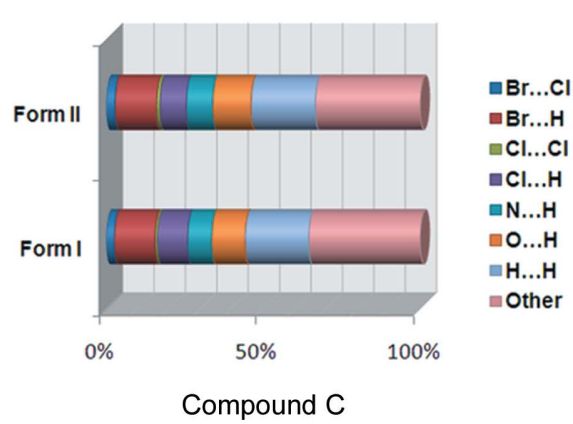

Figure 14

Hirshfeld surface analysis for polymorphs of Compounds-A, -B and -C, showing the contributions of the different hydrogen- and halogen-bonding interactions. 
response is ascribed to the rapid release of accumulated strain during the phase transition and anisotropy in the structural parameters.

\subsection{Photochromism}

Photochromism (Safin et al., 2014; Cohen et al., 1964; Senier \& Shepheard, 1909; Zbačnik \& Kaitner, 2014) of both organic and inorganic materials is defined as the reversible colour change of a material on exposure to electromagnetic radiation such as UV, visible light or IR. The sensitivity of such materials towards light makes them potential candidates in reusable information storage media, data displays, chemical switches for computers etc. (Gust et al., 2012; Kawata \& Kawata, 2000). The salinazid derivatives presented in this study show thermochromic and photochromic behaviour in the solid state.

The accepted mechanism for photochromism is the transfer of a proton to the $\mathrm{N}$ atom (cis-keto) followed by isomerization of cis-keto to trans-keto isomers (Scheme 4) (Hadjoudis \& Mavridis, 2004). The dihedral angle between two phenyl rings is the predictor for photochromism. If the angle is $>30^{\circ}$ then the compounds are photochromic, if the angle is $20-30^{\circ}$ the compounds are either photochromic or non-photochromic, and if the angle is $<20^{\circ}$ then the compounds are non-photochromic (Carletta et al., 2016). The polymorphs of CompoundB show photochromism in the solid state during exposure to UV light (365 nm). The dihedral angles in Form I and Form II are $15^{\circ}$ and $42^{\circ}$, respectively, and the former crystal is cyan in colour and the latter is light orange (Fig. 15).

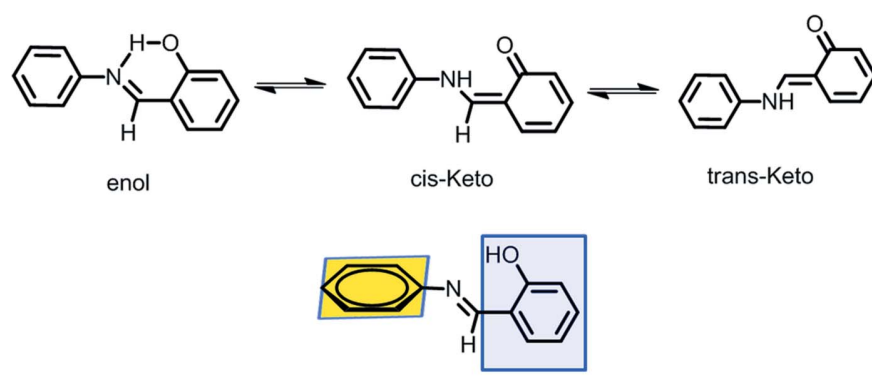

Scheme 4

\section{Conclusions}

In the present investigation we have explored the mechanical response of organic crystals towards thermal stress and the role of type II halogen bonding in tuning the properties of materials. The dichloro (Form I) derivative of the Schiff base shows excellent thermal effects, and a decrease in thermal effects was observed with the more polarizable (and less electronegative) iodine in the order $\mathrm{Cl} \cdots \mathrm{Cl}>\mathrm{Br} \cdots \mathrm{Cl}>$ $\mathrm{Br} \cdot \mathrm{Br}>\mathrm{I} \cdot \cdots \mathrm{I}$. These effects are ascribed to anisotropy in the cell parameters and to the sudden release of accumulated strain during the phase transition. Our results demonstrate the importance of weak halogen-bonding interactions $(\mathrm{Cl} \cdots \mathrm{Cl})$ of the type II variety in a family of thermally stable and highly reversible self-actuating materials.
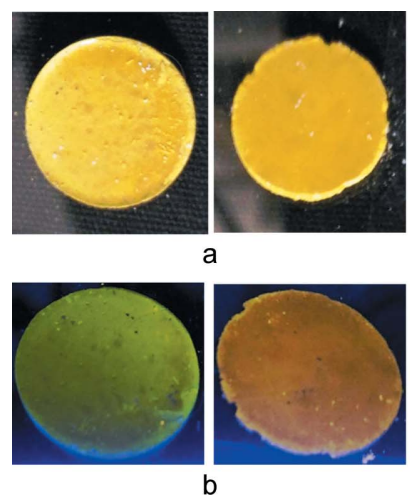

Figure 15

(Left) Compound-B Form I and Form II ( $a$ ) under normal light and $(b)$ under UV at $365 \mathrm{~nm}$. (Right) The variation in the conformation of the molecule.

\section{Acknowledgements}

S. Mittapalli and D. Sravanakumar Perumalla thank the UGC for Fellowships. J. B. Nanubolu thanks CSIR-IICT, Hyderabad, for facilities. Dr Rajesh G. Gonnade (CSIR-NCL, Pune) is thanked for single-crystal X-ray analysis of Compound-A (Form III) and Compound-C (Form II) at high temperature. We thank the SERB Scheme on Multi-component Crystals (EMR/2015/002075) and the J. C. Bose Fellowship (SR/S2/ JCB-06/2009) for funding.

\section{Funding information}

The following funding is acknowledged: JC Bose fellowship. Bose Centre for Advanced Study and Research in Natural Sciences, University of Dhaka (scholarship No. SR/S2/JCB-06/ 2009).

\section{References}

Barbour, L. J. (1999). X-SEED. University of Missouri-Columbia, Missouri, USA.

Bruker AXS Inc. (2000). SMART (Version 5.625) and SHELXTL (Version 6.12). Bruker AXS Inc., Madison, Wisconsin, USA.

Bui, T. T. T., Dahaoui, S., Lecomte, C., Desiraju, G. R. \& Espinosa, E. (2009). Angew. Chem. Int. Ed. 48, 3838-3841.

Cabane, E., Zhang, X., Langowska, K., Palivan, C. G. \& Meier, W. (2012). Biointerphases, 7, 9.

Carletta, A., Buol, X., Leyssens, T., Champagne, B. \& Wouters, J. (2016). J. Phys. Chem. C, 120, 10001-10008.

Chopra, D. \& Row, T. N. G. (2011). CrystEngComm, 13, 2175-2186.

Cohen, M. D., Schmidt, G. M. J. \& Flavian, S. (1964). J. Chem. Soc. 0, 2041-2051.

Das, D., Jacobs, T. \& Barbour, L. J. (2010). Nat. Mater. 9, 36-39.

Desiraju, G. R. \& Parthasarathy, R. (1989). J. Am. Chem. Soc. 111, 8725-8726.

Dikundwar, A., Sathishkumar, R. \& Row, T. N. G. (2014). Z. Kristallogr. 229, 609-624.

Etter, M. C. \& Siedle, A. R. (1983). J. Am. Chem. Soc. 105, 641-643.

Frisch, M. J., Trucks, G. W., Schlegel, H. B., Scuseria, G. E., Robb, M. A., Cheeseman, J. R., Scalmani, G., Barone, V., Mennucci, B. \& Petersson, G. A. (2009). Gaussian09, Revision A.02, Gaussian, inc., Wallingford, Connecticut, USA. 
Gelbrich, T., Threlfall, T. L. \& Hursthouse, M. B. (2012). CrystEngComm, 14, 5454-5464.

Gust, D., Andréasson, J., Pischel, U., Moore, T. A. \& Moore, A. L. (2012). Chem. Commun. 48, 1947-1957.

Hadjoudis, E. \& Mavridis, I. M. (2004). Chem. Soc. Rev. 33, 579-588.

Ikeda, T., Mamiya, J. \& Yu, Y. (2007). Angew. Chem. Int. Ed. 46, 506528.

Kawata, S. \& Kawata, Y. (2000). Chem. Rev. 100, 1777-1788.

Kim, T., Al-Muhanna, M. K., Al-Suwaidan, S. D., Al-Kaysi, R. O. \& Bardeen, C. J. (2013). Angew. Chem. Int. Ed. 52, 6889-6893.

Koshima, H., Ojima, N. \& Uchimoto, H. (2009). J. Am. Chem. Soc. 131, 6890-6891.

Kumar, S. S., Rana, S. \& Nangia, A. (2013). Chem. Asian J. 8, 15511568.

Lehn, J. M. (2002). Science, 295, 2400-2403.

Lieberman, H. F., Davey, R. J. \& Newsham, D. M. T. (2000). Chem. Mater. 12, 490-494.

Lusi, M. \& Bernstein, J. (2013). Chem. Commun. 49, 9293-9295.

Mao, Y., Ding, Z., Yuan, C., Ai, S., Isakov, M., Wu, J., Wang, T., Dunn, M. L. \& Qi, H. J. (2016). Sci. Rep. 6, 24761.

Mather, P. T. (2007). Nat. Mater. 6, 93-94.

McCrone, W. C. (1965). Physics and Chemistry of the Organic Solid State, Vol. 2, edited by D. Fox, M. M. Labes \& A. Weissberger, pp. 725-767. NewYork: Interscience.

Medishetty, R., Sahoo, S. C., Mulijanto, C. E., Naumov, P. \& Vittal, J. J. (2015). Chem. Mater. 27, 1821-1829.

Metrangolo, P. \& Resnati, G. (2014). IUCrJ, 1, 5-7.

Baker, E. N. (2017). IUCrJ, 4, 1-2.

Morimoto, M. \& Irie, M. (2010). J. Am. Chem. Soc. 132, 14172-14178.

Mukherjee, A. \& Desiraju, G. R. (2014). IUCrJ, 1, 49-60.

Nath, N. K., Panda, M. K., Sahoo, S. C. \& Naumov, P. (2014). CrystEngComm, 16, 1850-1858.

Nauha, E. \& Bernstein, J. (2014). Cryst. Growth Des. 14, 4364-4370.

Naumov, P., Chizhik, S., Panda, M. K., Nath, N. K. \& Boldyreva, E. (2015). Chem. Rev. 115, 12440-12490.

Panda, M. K., Centore, R., Causà, M., Tuzi, A., Borbone, F. \& Naumov, P. (2016). Sci. Rep. 6, 29610.

Panda, M. K., Runčevski, T., Husain, A., Dinnebier, R. E. \& Naumov, P. (2015). J. Am. Chem. Soc. 137, 1895-1902.
Park, Y., Gutierrez, M. P. \& Lee, L. P. (2016). Sci. Rep. 6, 39402.

Rowan, S. J. (2009). Nat. Chem. 1, 347-348.

Safin, D. A., Babashkina, M. G., Robeyns, K., Bolte, M. \& Garcia, Y. (2014). CrystEngComm, 16, 7053-7061.

Sagara, Y. \& Kato, T. (2009). Nat. Chem. 1, 605-610.

Saha, B. K., Nangia, A. \& Nicoud, J. F. (2006). Cryst. Growth Des. 6, 1278-1281.

Sahoo, S. C., Panda, M. K., Nath, N. K. \& Naumov, P. (2013). J. Am. Chem. Soc. 135, 12241-12251.

Saraswatula, V. G. \& Saha, B. K. (2014). New J. Chem. 38, 897-901.

Sato, O. (2016). Nat. Chem. 8, 644-656.

Senier, A. \& Shepheard, F. G. (1909). J. Chem. Soc. Trans. 95, 441445.

Sheldrick, G. M. (1997a). SADABS. University of Göttingen, Göttingen, Germany.

Sheldrick, G. M. (1997b). SHELXS97 and SHELXL97. University of Göttingen, Göttingen, Germany.

Skoko, Z., Zamir, S., Naumov, P. \& Bernstein, J. (2010). J. Am. Chem. Soc. 132, 14191-14202.

Spek, A. L. (2002). PLATON. Utrecht University, Utrecht, The Netherlands.

Swapna, B., Suresh, K. \& Nangia, A. (2016). Chem. Commun. 52, 4037-4040.

Takashima, Y., Hatanaka, S., Otsubo, M., Nakahata, M., Kakuta, T., Hashidzume, A., Yamaguchi, H. \& Harada, A. (2012). Nat. Commun. 3, 1270.

Takeda, T. \& Akutagawa, T. (2016). Chem. Eur. J. 22, 77637770 .

Thalladi, V. R., Weiss, H. C., Bläser, D., Boese, R., Nangia, A. \& Desiraju, G. R. (1998). J. Am. Chem. Soc. 120, 8702-8710.

Uchida, K., Sukata, S., Matsuzawa, Y., Akazawa, M., de Jong, J. J. D., Katsonis, N., Kojima, Y., Nakamura, S., Areephong, J., Meetsma, A. \& Feringa, B. L. (2008). Chem. Commun. 0, 326-328.

Yao, Z.-S., Mito, M., Kamachi, T., Shiota, T., Yoshizawa, K., Azuma, N., Miyazaki, Y., Takahashi, K., Zhang, K., Nakanishi, T., Kang, S., Kanegawa, S. \& Sato, O. (2014). Nat. Chem. 6, 1079-1083.

Zbačnik, M. \& Kaitner, B. (2014). CrystEngComm, 16, 41624168.

Zhao, Y. \& Truhlar, D. (2008). Theor. Chem. Acc. 120, 215-241. 